\title{
Simulation and Optimization of an Ammonia Plant: A Case Study of Indorama Ammonia Plant
}

\section{Article History}

Received: 08.11.2020

Accepted: 19.11 .2020

Published: 24.11.2020

Journal homepage:

https://www.easpublisher.com/

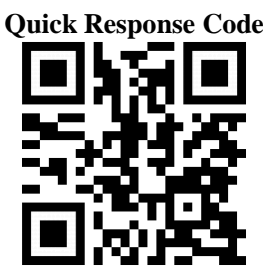

Abstract: A functional industrial ammonia plant has been simulated using the plant data. All the unit operations, including definition and formation of reactions set have been performed in Aspen HYSYS V8.8. The simulated results compared with the plant data indicate reasonable agreement. The process optimization was performed using the optimization techniques such as BOX, Mixed and Sequential Quadratic Programming in Aspen HYSYSV8.8. The SQP, Mixed and BOX optimization algorithms gave optimum variables at quick convergence with reasonable iterative numbers. It was therefore deduced that the SQP, Mixed and BOX algorithms were more appropriate for the multi-step ammonia process. From the algorithms, the optimum operating conditions that increased the yield of ammonia production are $43.97^{\circ} \mathrm{C}, 4839 \mathrm{kPa}$ and $25670 \mathrm{~kg} / \mathrm{hr}$ for natural gas and $280.6^{\circ} \mathrm{C} 21490.0 \mathrm{kPa}$ for the ammonia production respectively given the percentage of ammonia to increase from 24.37 to 41.04 mole percent. The performance criterion which was Energy consumption was the objective function which was minimized in the reforming sections. The results showed that there was reduction of energy from $125.36 \mathrm{Gcal} / \mathrm{hr}$ to $75.095 \mathrm{Gcal} / \mathrm{hr}$ in the primary reformer and from $43.021 \mathrm{Gcal} / \mathrm{hr}$ to $34.37 \mathrm{Gcal} / \mathrm{hr}$ in the secondary reformer respectively. The effect of process parameters on the component performance was performed. It was observed that temperature, pressure and mass flow rate of the natural gas greatly influenced the yield of ammonia. Comparison of the plant, simulated and optimized results were done in terms of operating process parameters and compositions of sour gas, desulfurized gas and ammonia synthesis converter products.

Keywords: Simulation, Optimization algorithms, Ammonia, Syngas, Hydrogen, Nitrogen, Carbon Oxides.

Copyright (C) 2020 The Author(s): This is an open-access article distributed under the terms of the Creative Commons Attribution 4.0 International License (CC BY-NC 4.0) which permits unrestricted use, distribution, and reproduction in any medium for non-commercial use provided the original author and source are credited.

\section{INTRODUCTION}

The operation of commercial industrial chemical processes required optimum operating conditions for the high yield and products purity. These operating process parameters such as temperature, pressure and mass flow rate are important for the efficient performance of a unit operation. Basically, Ammonia is produced industrially from the advent of process technology by the Haber- Bosch process where the molecular hydrogen is combined with molecular Nitrogen in the ratio of 3:1 to yield ammonia $[1,3]$. To reduce cost and time in chemical plants chemical as well as process engineers used simulators to simulate design and operate process equipment and plant. The mostly used simulator for chemical processes is the Aspen HYSYS that is used for both design and operations. Simulation of ammonia synthesis is done using R-LNG on Aspen HYSYS V8.8 with steady state mode and assumptions using hypothetical reactors [1].

In the work [2], the law of conservation of mass and energy was used to determine the mass and energy balances of the plant, simulation of the plant was done with Plant Design Management System (PDMS) through Haldor Topsoe process route. The design analysis obtained production capacity of 640,288.80 metric tons per year (MTPY) and the energy required to convert the synthesis gas into ammonia was $2414112233.8 \mathrm{~kJ} / \mathrm{hr}$. Commercial ammonia plants use steam reforming coal gasification or R-LNG as source of nitrogen and hydrogen for the Haber - Bosch synthesis loop, the nitrogen and hydrogen mixed with carbon oxides are called synthesis gas [2].

Dsai et al. [3], performed simulation and energy optimization of ammonia synthesis loop, the proposed kinetic model was used to develop SciLab simulation for the various output parameters at different feed flow rate.

Lundgren and Hillestaad [9] performed work on Incorporating Ammonia synthesis for an offshore Gas-to-Liquid process, in which two possible designs were tentatively suggested and evaluated. The process design features a synthesis loop as well as removal of 
compounds containing oxygen, such as $\mathrm{CO}_{2}$ and water as these components are poisonous to the ammonia synthesis catalyst. The ammonia synthesis was simulated as three separate beds, with a refrigeration loop to cool the stream exiting the reactor to sub-zero temperatures in order for ammonia and unreacted hydrogen and nitrogen gas is recycled and reintroduced to the reactor. The two separate process designs were simulated in Aspen HYSYS V8.6, each with a different source of nitrogen.

HYSYS model representing the steady state behavoiur of a Haber-Bosch plant was developed based on the dynamic model and Plant data from Norwegian Fertilizer Company Yara international ASA. Unit of operations such as synthesis gas makeup, reaction, separation and refrigeration sections the plant model was optimized using MATLAB function with an interior-point method for economical optimization to study the performance of different strategies [4].

The Packed- Bed model was developed to predict the mole fraction, temperature, and pressure profiles from a Fertilizer company of south Basrah. The effectiveness factor of the reactions showed good results of the simulation [2].

Also in another work performed by Bicer [5] on the investigation of novel ammonia production options using photo-electrochemical hydrogen. Bicer concluded that the results obtained from the combination of thermodynamic, thermo-economic, electrochemical and life cycle models of the integrated system are successful. He also calculated the exergy efficiencies and the total cost of the ammonia production using exergy-economic and concluded that the method is economically feasible.

The significance of this study is stemmed to the fact that there was an increased demand for fertilizers in Nigeria and other developing countries due to increased population, high living standards and urbanization [6]. Lower agricultural productivity because of reduction in soil nutrients and oil spillage. Increased demand for ammonia due to industrial purposes such as production of chemicals, pulp \& paper, Fibers \& plastics, Explosives, Mining and Metallurgy, etc

Akpa and Raphael [8], Carried out optimization of an ammonia synthesis convertor. A model to determine optimal inlet temperature of the catalyst beds was developed. The objective function is to maximize the fractional conversion of nitrogen on the four catalyst beds of the converter subject to variation of the inlet temperature to each catalyst bed. An iterative procedure was used to update the initial values of inlet temperature for accurate results and quick convergence.
In this study, the production of ammonia utilized the Kellogg Brown and Root Advanced Purifier Process, a low energy natural gas reforming. This process gave remarkable increase of mole percent when it was optimized. It provided operational cost savings when the load on the syn loop and refrigeration systems was reduced by providing a clean dry makeup syngas. The reforming section was not controlled providing a precise $\mathrm{H}_{2} / \mathrm{N}_{2}$ ratio. The reforming temperature is low thus, resulted in lower stresses and longer life of reformer tubes therefore plant can run or operate 3-4 years before turn- around maintenance. There is also low inert that gives high loop conversion.

The main objective of this study was to determine the optimum operating parameters that can increase the yield of ammonia in the Indorama ammonia plant using Aspen HYSYS Version 8.8. Thus optimization is imminent if the quantity and quality of the products that will meet desired specifications were to be achieved [7].

\section{Materials ANd MethodS Materials}

The materials used for this study were the operating data and process description that shows all the equipment and utilities from Indorama Fertilizer and Chemicals Company. The simulation and optimization were done using Aspen HYSYS version 8.8 simulators.

\section{Methods \\ Process Simulation}

The main steps for the ammonia process simulation are; selection of component list, selection of fluid package, defining and formation of reactions sets, and installing the feed streams and connecting the flow sheet [1].

\section{Process Optimization}

The setup of the process optimization from simulated model with the aid of Aspen HYSYS to predict or determine the optimum parameters that increased the yield of ammonia production in the Indorama Ammonia plant is shown in Figure1. The procedure of the process optimization is as follows: selection of the streams and unit operations from the simulated model; selection and importation of the manipulated variables from the selected units of the plant as shown in Table1, the manipulated variable of the optimization were the temperature, pressure, and flow rate of the natural gas stream, and the temperature and pressure of the process steam, process air, and ammonia synthesis converter stream respectively. The objective function was the minimization of energy consumption in the reforming sections using the optimizer algorithms such as BOX, Mixed, and Sequential Quadratic Programming (SQP). 


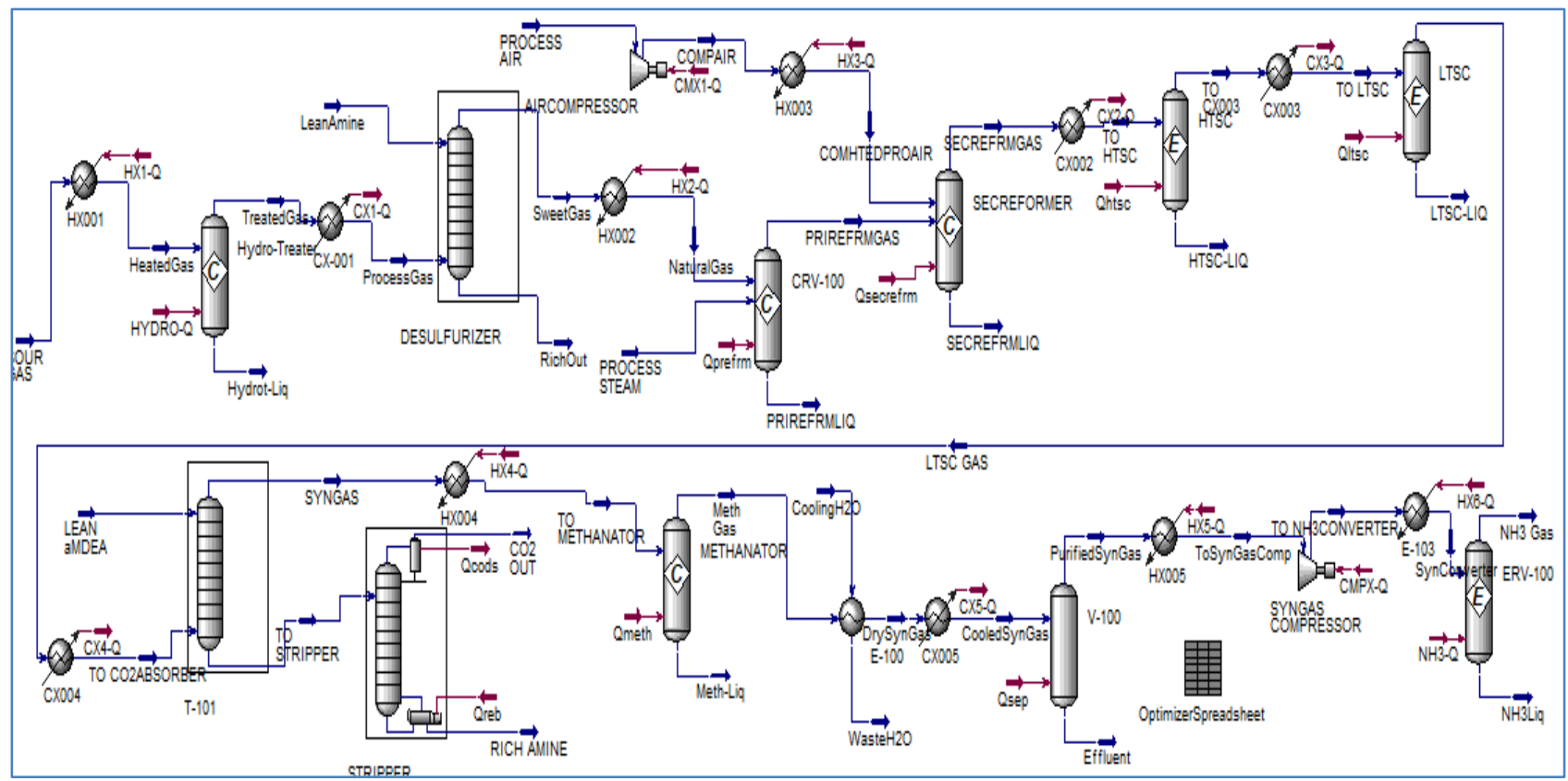

Fig-1: Building of the Ammonia Process into Aspen HYSYS

Tale-1: Setting the Lower and upper bounds of the manipulated variables

\begin{tabular}{|llll|}
\hline Stream & Parameters & Lower bound & Upper bound \\
\hline Natural Gas & Temperature & 25 & 85 \\
& Pressure & 3600 & 9610 \\
& Mass flow & 25670 & 93000 \\
Process Air & Temperature & 160.5 & 642.0 \\
& Pressure & 2233 & 8931 \\
Process Steam & Temperature & 255.0 & 1020 \\
& Pressure & 4700 & 9402 \\
Ammonia Converter & Temperature & 250 & 840 \\
Pressure & & 7747 & 21490 \\
\hline
\end{tabular}

\section{RESULTS AND DISCUSSION Simulation and Optimization}

The steady state simulation of the Indorama Ammonia plant provides the results that best described the approximate behavior of the operations of the system over time. Table 2 shows the comparison of the composition of the Sweet gas stream. The sour gas was fed at a temperature of $50^{\circ} \mathrm{C}$ and pressure of $4805 \mathrm{kPa}$; it was preheated at a temperature of $460^{\circ} \mathrm{C}$ before entering the mercaptan conversion unit which provided the results shown in Table2. The result was able to show a remarkable increase in the natural gas mole percent that exit the desulfurizer unit.

Table-2: Shows the process parameters comparison between the simulated and optimized results of the natural gas stream

\begin{tabular}{|lll|}
\hline Parameters & Simulated & Optimized \\
\hline Vapour fraction & 1.0000 & 1.0000 \\
Temperature $\left({ }^{\circ} \mathrm{C}\right)$ & 50.000 & 43.97 \\
Pressure $(\mathrm{kPa})$ & 4805 & 3643 \\
Mass flow $(\mathrm{kg} / \mathrm{hr})$ & 51340 & 25670 \\
Heat flow $(\mathrm{kJ} / \mathrm{hr})$ & $-1.972 \mathrm{e}+8$ & $-9.705 \mathrm{e}+7$ \\
\hline
\end{tabular}

It is observed from Table 2 that the simulated results showed significance similarity with the plant process parameters. When the process was optimized, the temperature reduces leading to an increase in the moles of the syngas production in the primary reformer.
According to le Chatelier's principle which states that decrease in temperature favours forward reaction of a gaseous process. It was also observed that reduction in energy was efficient for the performance of the process. 
Table-3: Natural Gas Composition for the Plant data, Simulated and Optimized Results

\begin{tabular}{|l|l|l|l|}
\hline Mole & Sour Gas Stream & \multicolumn{2}{|c|}{ Sweet Gas Stream } \\
\cline { 3 - 4 } (Plant Data ) & Simulated & Optimized \\
\hline Methane & 0.8980 & 0.9589 & 0.9714 \\
$\mathrm{CO}_{2}$ & 0.0000 & 0.0000 & 0.0000 \\
$\mathrm{CO}$ & 0.0000 & 0.0000 & 0.0000 \\
$\mathrm{H}_{2} \mathrm{~S}$ & 0.0000 & 0.0168 & 0.0036 \\
$\mathrm{H}_{2} \mathrm{O}$ & 0.0000 & 0.0011 & 0.0011 \\
$\mathrm{Air}$ & 0.0000 & 0.0000 & 0.0000 \\
Nitrogen & 0.0000 & 0.0000 & 0.0000 \\
Hydrogen & 0.0300 & 0.0011 & 0.0000 \\
Argon & 0.0010 & 0.0011 & 0.0011 \\
Oxygen & 0.0200 & 0.0211 & 0.0217 \\
COS & 0.0010 & 0.0000 & 0.0000 \\
Mercaptan & 0.0500 & 0.0000 & 0.0000 \\
\hline Total & 1.0000 & 1.0000 & 1.0000 \\
\hline
\end{tabular}

Table-4: Comparison of Predictions from Simulated and Optimized Cases with Plant data

\begin{tabular}{|lccc|}
\hline Mole Fraction & Plant Data & Simulated Case & Optimized Case \\
\hline Methane & 0.2980 & 0.0508 & 0.0320 \\
$\mathrm{CO}_{2}$ & 0.0490 & 0.0562 & 0.0355 \\
$\mathrm{CO}$ & 0.0630 & 0.0701 & 0.0442 \\
$\mathrm{H}_{2} \mathrm{~S}$ & 0.0000 & 0.0085 & 0.0003 \\
$\mathrm{H}_{2} \mathrm{O}$ & 0.0509 & 0.3919 & 0.6184 \\
$\mathrm{Air}$ & 0.0000 & 0.0000 & 0.0000 \\
Nitrogen & 0.0000 & 0.0000 & 0.0000 \\
Hydrogen & 0.5390 & 0.4233 & 0.2695 \\
Argon & 0.0001 & 0.0001 & 0.0001 \\
COS & 0.0000 & 0.0000 & 0.0000 \\
Mercaptan & 0.0000 & 0.0000 & 0.0000 \\
\hline Total & 1.0000 & 1.0000 & 1.0000 \\
\hline
\end{tabular}

In Table 3, there was the production of considerable amount of synthesis gas due to the reaction of steam with methane. The results show that for the Aspen HYSYS simulation, natural gas is converted than in the plant and more conversion occurred when the process was optimized.
Increase in the formation of syngas was actually due to increase in pressure according to le Chatelier's principle, the reaction goes to the direction where hydrogen is being produced.

Table 4. below depicts secondary reformer composition comparison between the simulated and optimized results

Table-4: Comparison between the Simulated and Optimized Results for the Secondary Reformer

\begin{tabular}{|l|c|c|}
\hline Mole Fraction & Simulated Case & Optimized Case \\
\hline Methane & 0.0000 & 0.0000 \\
$\mathrm{CO}_{2}$ & 0.0341 & 0.0177 \\
$\mathrm{CO}$ & 0.0468 & 0.0275 \\
$\mathrm{H}_{2} \mathrm{~S}$ & 0.0014 & 0.0001 \\
$\mathrm{H}_{2} \mathrm{O}$ & 0.1650 & 0.2445 \\
$\mathrm{Air}$ & 0.0000 & 0.0000 \\
Nitrogen & 0.1264 & 0.1438 \\
Hydrogen & 0.6097 & 0.5430 \\
Argon & 0.0001 & 0.0001 \\
Oxygen & 0.0165 & 0.0234 \\
Ammonia & 0.0000 & 0.0000 \\
\hline Total & 1.0000 & 1.0000 \\
\hline
\end{tabular}

It is observed from Table4 that the amount of nitrogen formed increased when the process was optimized. The results show that methane completely reacted with steam and air was also compressed to produce nitrogen and hydrogen. When the process was optimized, the amount of nitrogen increased from 12.04 mole percent to 14.38 mole percent. It is observed that 
the amount of hydrogen reduced due to temperature rise in the reformer.

Table5 below shows the comparison between the simulated results with the optimized results of the High and Low Shift Converter in terms of Composition.
In this unit, carbon monoxide reacted with steam to form hydrogen and carbon dioxide according to the following equation $\mathrm{CO}+\mathrm{H}_{2} \mathrm{O} \rightarrow \mathrm{CO}_{2}+\mathrm{H}_{2}$. The same equation was used for the simulation of the two shift reactions in this unit

Table-5: Composition Comparison of the Simulated Results with Optimized Results of the High and Low Temperature Shift Converter

\begin{tabular}{|l|c|c|c|c|}
\hline Mole fraction & \multicolumn{2}{|c|}{ Simulated Case } & \multicolumn{2}{c|}{ Optimized Case } \\
\hline & HTSC & LTSC & HTSC & LTSC \\
\hline Methane & 0.0000 & 0.0000 & 0.0000 & 0.0000 \\
$\mathrm{CO}_{2}$ & 0.0625 & 0.0902 & 0.0389 & 0.0566 \\
$\mathrm{CO}$ & 0.0184 & 0.0007 & 0.0062 & 0.0004 \\
$\mathrm{H}_{2} \mathrm{~S}$ & 0.0014 & 0.0016 & 0.0002 & 0.0002 \\
$\mathrm{H}_{2} \mathrm{O}$ & 0.1366 & 0.0082 & 0.2231 & 0.0082 \\
Air & 0.0000 & 0.0000 & 0.0000 & 0.0000 \\
Nitrogen & 0.1264 & 0.1423 & 0.1438 & 0.1823 \\
Hydrogen & 0.6381 & 0.7383 & 0.5643 & 0.7225 \\
Argon & 0.0001 & 0.0001 & 0.0001 & 0.0001 \\
Oxygen & 0.0165 & 0.0186 & 0.0234 & 0.0297 \\
Ammonia & 0.0000 & 0.0000 & 0.0000 & 0.0000 \\
\hline \multicolumn{2}{|c|}{1.0000} & 1.0000 & 1.0000 & 1.0000 \\
\hline
\end{tabular}

From Table 5, it is observed that decreased in temperature from $371^{\circ} \mathrm{C}$ to $205^{\circ} \mathrm{C}$ increased the amount of Carbon dioxide formed thereby increases the mole of hydrogen and nitrogen in the Low Temperature Shift Converter unit. This indicates that equivalent formation of hydrogen and carbon dioxide is a reversible exothermic reaction of steam and carbon dioxide as also seen in the primary reforming section. The results also showed that the amount of hydrogen increased from
56.43 to 72.25 moles percent and nitrogen from 14.38 to 18.23 moles percent respectively.

Table6 shows the composition difference between the simulated and optimized results of the Methanator. In the simulation of the methanator unit, the remaining carbon oxides combine with hydrogen to form methane and water.

\section{Table-6: Comparison of the Simulated and Optimized Results of the Methanator Unit Based on Composition}

\begin{tabular}{|lcc|}
\hline Mole Fraction & Simulated Case & Optimized Case \\
\hline Methane & 0.1114 & 0.0644 \\
$\mathrm{CO} 2$ & 0.0000 & 0.0000 \\
$\mathrm{CO}$ & 0.0000 & 0.0000 \\
$\mathrm{H} 2 \mathrm{~S}$ & 0.0019 & 0.0002 \\
$\mathrm{H} 2 \mathrm{O}$ & 0.2248 & 0.1306 \\
Nitrogen & 0.1751 & 0.2071 \\
Hydrogen & 0.4639 & 0.5639 \\
Argon & 0.0001 & 0.0001 \\
Oxygen & 0.0228 & 0.0337 \\
Ammonia & 0.0000 & 0.0000 \\
\hline Total & 1.0000 & 1.0000 \\
\hline
\end{tabular}

From Table 6, it is observed that carbon dioxide reacted with hydrogen to form methane and water because in the low temperature shift conversion. This was done to remove carbon dioxide that would act as catalyst poison in the synthesis loop. This results in the increase of the mole percent of nitrogen when the process was optimized. There was also a low amount of reactant in the synthesis gas; there was a fairly large temperature rise in the component.

Table 7 shows the comparison between the simulated and optimized results of the composition in the synthesis converter 
Table-7: Composition Results of the Simulated and the Optimized Ammonia Synthesis Converter

\begin{tabular}{|lcc|}
\hline Mole Fraction & Simulated Case & Optimized Case \\
\hline Methane & 0.1385 & 0.0908 \\
$\mathrm{CO}_{2}$ & 0.0000 & 0.0000 \\
$\mathrm{CO}$ & 0.0000 & 0.0000 \\
$\mathrm{H}_{2} \mathrm{~S}$ & 0.0024 & 0.0003 \\
$\mathrm{H}_{2} \mathrm{O}$ & 0.2796 & 0.1841 \\
Nitrogen & 0.0959 & 0.0869 \\
Hydrogen & 0.2114 & 0.1798 \\
Argon & 0.0001 & 0.0001 \\
Oxygen & 0.0284 & 0.0475 \\
Ammonia & 0.2437 & 0.4104 \\
\hline Total & 1.0000 & 1.0000 \\
\hline
\end{tabular}

From Table7 above, it could be deduced that both hydrogen and nitrogen actually reacted to form ammonia when the process was simulated. The amount of ammonia produced increase from 24.37 to 41.04 mole percent when the process was optimized. According to Le Chatelier's principle, rise of temperature cause the production of ammonia to reduce in the unit, but when the process was optimized the amount of ammonia increases due to high pressure. Thus it is deduced that high pressure favoured the ammonia production.
Table 8 below shows the optimum parameters of both natural gas and ammonia synthesis convert that increase the yield of ammonia production.

The simulation results obtained is required to determine the optimum parameters that will give high yield of the ammonia mole percent. Three optimization algorithms such as SQP, Mixed, BOX, were employed to determine the optimum solution.

Table-3.8: The Optimum Parameters that Increase the Yield of Ammonia gas

\begin{tabular}{|c|c|c|c|c|c|c|}
\hline \multicolumn{2}{|c|}{ Iteration No. } & \multicolumn{2}{|c|}{ Natural Gas Parameter } & \multicolumn{3}{|c|}{ Ammonia Gas Parameters } \\
\hline & $\begin{array}{c}\text { Flow } \\
\text { rate } \\
(\mathbf{k g} / \mathbf{h r})\end{array}$ & Temperature $\left({ }^{\circ} \mathrm{C}\right)$ & Pressure (kPa) & Temperature $\left({ }^{\circ} \mathrm{C}\right)$ & Pressure (kPa) & Mole Fraction \\
\hline 1 & 5130 & 50.0 & 48050 & 450 & 15494.5 & 0.1985 \\
\hline 2 & 3110 & 27.5 & & 402 & 19617.3 & 0.2437 \\
\hline 3 & 2560 & 43.97 & 4781.3 & 280.6 & 21490.0 & 0.4533 \\
\hline 4 & 2567 & 43.97 & $\begin{array}{l}4796.84 \\
4839.71\end{array}$ & 280.6 & 21490.0 & 0.4533 \\
\hline
\end{tabular}

It can be deduced from Table 8 that the amount of ammonia increases from 0.1985 to 0.4533 moles when the process parameters were optimized using the optimization techniques in Aspen HYSYS. The SQP, Mixed and BOX optimization algorithms gave optimum variables at quick convergence. There, it is deduced that SQP, Mixed and BOX were more appropriate for this complex ammonia process. These algorithms gave optimum parameters of temperature, pressure and mass flow rate as $43.97^{\circ} \mathrm{C}, 4839.71 \mathrm{kPa}$ and $25670.0 \mathrm{~kg} / \mathrm{hr}$ for natural gas and $280.6^{\circ} \mathrm{C}$, $21490.04 \mathrm{kPa}$, and $227800 \mathrm{~kg} / \mathrm{hr}$ for ammonia vapour that exited the synthesis converter respectively giving the percentage of ammonia to increase from 19.85 to 45.33 mole percent.

Table 9 shows that Aspen HYSYS simulation and optimization provides an option to estimate energy requirement for each unit operations for the actual performance of the process

Table-9: Comparison between Primary and Secondary Reformer in Terms of Energy Consumption

\begin{tabular}{|lccc|}
\hline Unit Operation & $\begin{array}{c}\text { Simulated Case } \\
\text { (Gcal/h) }\end{array}$ & $\begin{array}{c}\text { Optimized Case } \\
(\mathbf{G c a l} / \mathbf{h})\end{array}$ & $\begin{array}{c}\text { Plant Data } \\
(\mathbf{G c a l} / \mathbf{h})\end{array}$ \\
\hline Primary Reformer & 125.36 & 75.096 & 78.48 \\
Secondary Reformer & 43.021 & 34.37 & 84.5 \\
\hline
\end{tabular}

It could be deduced from Table 9 that the optimization algorithms result a specific energy reduction of $125.36 \mathrm{Gcal} / \mathrm{hr}$ to $75.096 \mathrm{Gcal} / \mathrm{hr}$ for the primary reformer and $43.021 \mathrm{Gcal} / \mathrm{hr}$ to $34.37 \mathrm{Gcal} / \mathrm{hr}$ for the secondary as compared with the plant data. The reduction in the energy consumption caused increase in the amount of ammonia production. 


\section{Effect of Process Parameters on the Ammonia} production

Process parameters are important in most process industries that have to maximize production yield and reduce cost of production or design of process equipment. This study has shown that process variables greatly affect production rate of ammonia.

Figurel below shows the effect of temperature of Sour gas on the rate of production of ammonia.

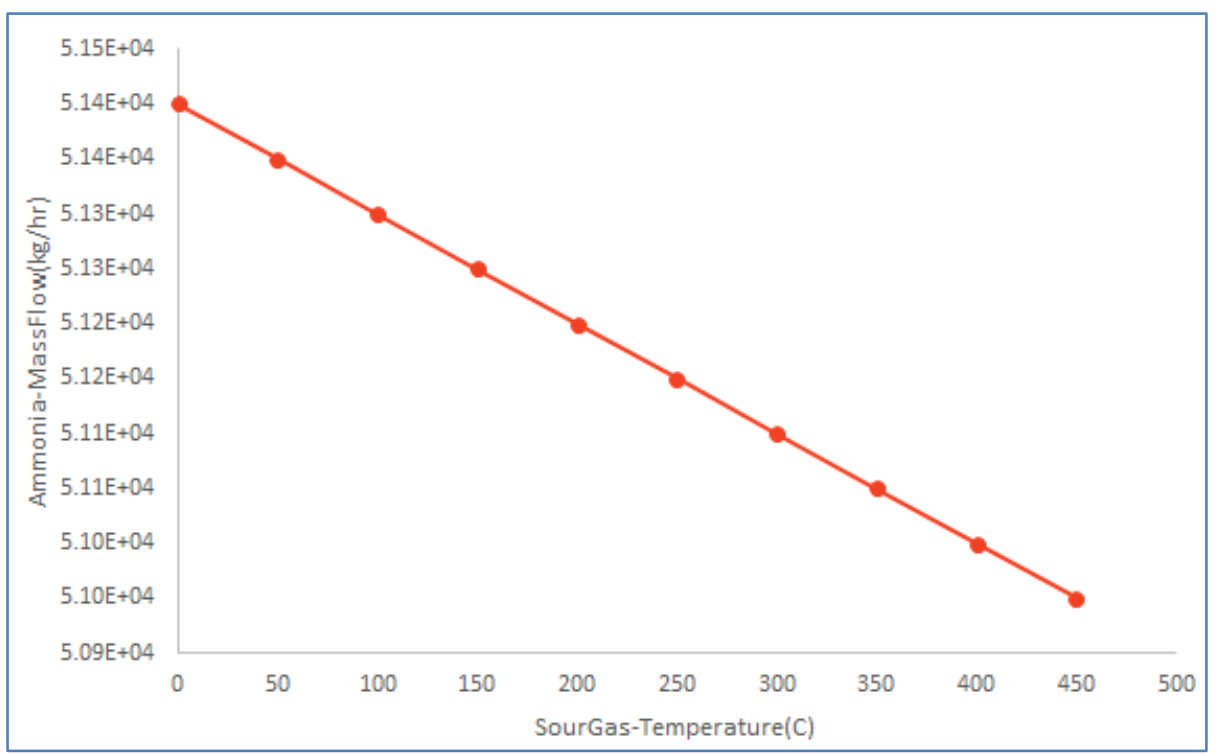

Fig-1: Mass flow rate of Ammonia Vs Temperature of Sour Gas

When temperature of the sour gas was increased, the mass flow rate of ammonia decreased because methane with high composition in the primary reformer raised the ratio of steam to carbon thus reduces the conversion of methane syngas. Following the Le Chatelier's principle, increased in temperature favoured the backward reaction of a gaseous process, therefore ammonia production was reduced

Figure 2 below shows how temperature of steam affects the ammonia production rate.

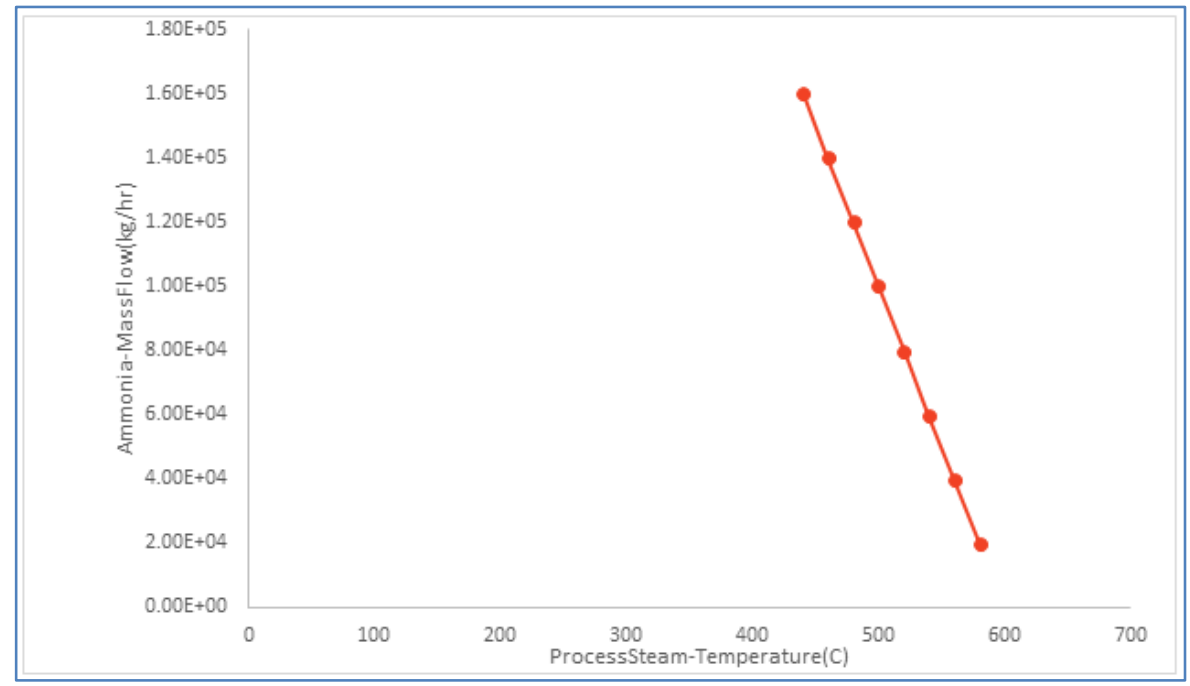

Fig-2: Mass flow rate of Ammonia Vs. Steam Temperature

From Figure 2 above it is observed that increase in the temperature of steam causes the decrease in ammonia production rate. As the temperature increase, the mass of ammonia gradually decreases. The effect of the temperature of air on the mass flow rate of ammonia is shown in Figure 3. 


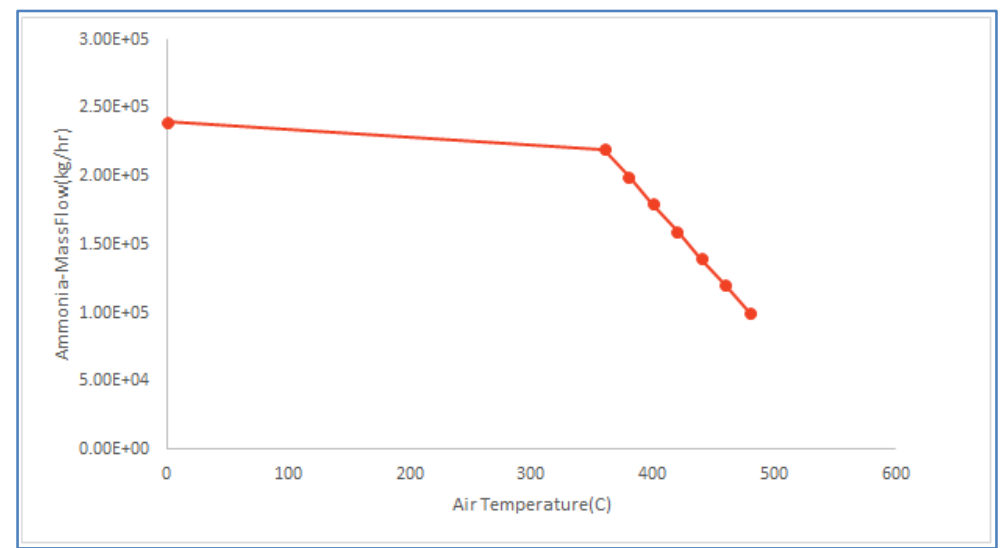

Fig-3: Mass flow rate of Ammonia Production Vs. Air Temperature

From Figure 3, it could be observed that as the temperature of air inlet stream was increased the mass of ammonia production decreased. It could be deduced that from Le Chatelier's principle, that exothermic reaction of air and methane favours the reversed side of the reaction.

Figure 4 below shows the effect of pressure of steam on ammonia production rate.

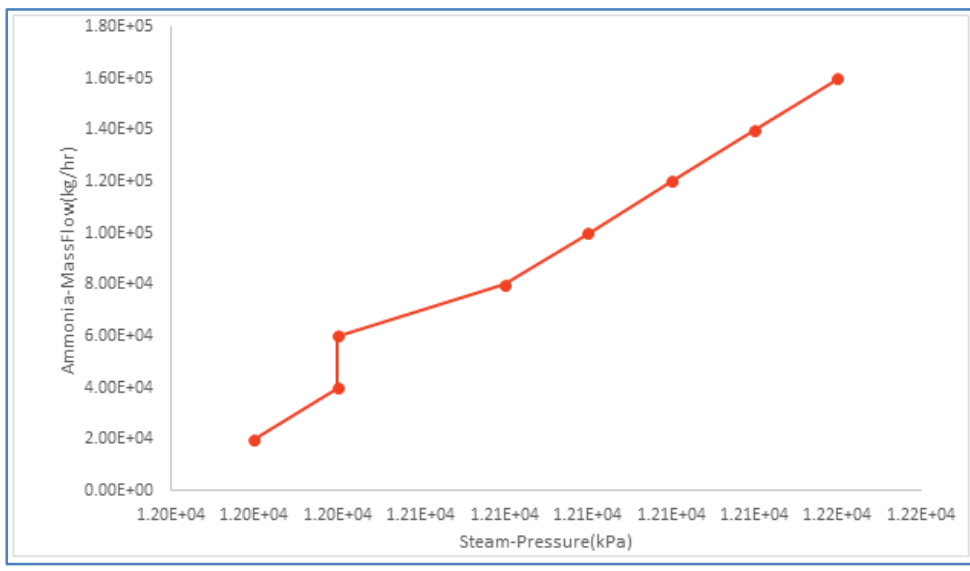

Fig-4: Steam Pressure against Production of Ammonia

As the steam pressure was increased, the amount of ammonia produced in the synthesis converter also increased. It could therefore be deduced that the forward reaction of hydrogen and nitrogen was favoured according to Le Chatelier's principle.
The Figure 5 shows the effect of pressure of air on the rate of ammonia production.

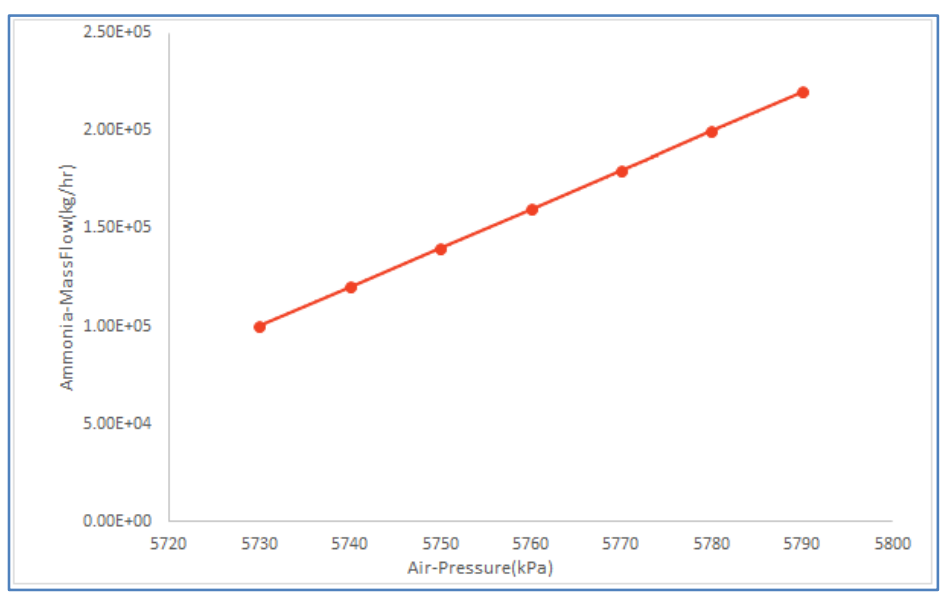

Fig-5: Mass flow rate of Ammonia Production against Air Pressure 
Figure 5 shows that when the air pressure is raised, the amount of ammonia being produced increases thus, the moles of reactants decreases progressively in the synthesis converter. But the amount of nitrogen in the secondary reformer is increased.

\section{Conclusions}

From the analysis of this study which are in line with the objectives, the following conclusion can be made:

i. Indorama ammonia plant has been simulated using the plant data. All the unit operations, including definition and formation of reactions set have been performed in Aspen HYSYS V8.8. The simulated results were compared with the plant data and it was observed that they were in strong agreement.

ii. The process optimization was performed using three optimization techniques such as BOX, Mixed and Sequential Quadratic Programming in Aspen HYSYSV8.8. The SQP, Mixed and BOX optimization algorithms gave optimum variables at quick convergence with reasonable iterative numbers. It is therefore deduced that the SQP, Mixed and BOX algorithms were more appropriate for this complex ammonia process. From the algorithms, the optimum process parameters that increase the yield of ammonia production are $43.97^{\circ} \mathrm{C}, 4839 \mathrm{Kpa}$ and $25670 \mathrm{~kg} / \mathrm{hr}$ for natural gas and $280.6^{\circ} \mathrm{C}$ $21490.0 \mathrm{KPa}$ for the ammonia production respectively given the percentage of ammonia to increase from 19.85 to 45.33 mole percent.

iii. The performance criterion which is Energy consumption is the objective function which was minimized in the reforming sections. The results showed that there is reduction of energy from $125.36 \mathrm{Gcal} / \mathrm{hr}$ to $75.095 \mathrm{Gcal} / \mathrm{hr}$ in the primary reformer and from $43.021 \mathrm{Gcal} / \mathrm{hr}$ to $34.37 \mathrm{Gcal} / \mathrm{hr}$ in the secondary reformer respectively.

iv. The effect of process parameters on the component performance was performed. It was observed that temperature, pressure and mass flow rate of the natural gas greatly affect the yield of ammonia.

v. Comparison of the plant, simulated and optimized results were done in terms of process parameters and compositions of sour gas, desulfurized gas and ammonia synthesis converter products.

\section{REFERENCES}

1. El-Moneim, N.A., Ismail, I., \& Nasser, M.M. (2020). Simulation of Ammonia Production using HYSYS Software. International Institute of Science, Technology and education Journal of Chemical and Process Engineering Research.62, 14-22. Retrieved from http:// www.iiste.org. Accessed 2020-08-23

2. Abdulrazzag, S.A., Abdulabbas, A.A. \& Al-Asadi. (2015). Modeling and Simulation of Methanation Catalytic Reactor in Ammonia Plant. International Journal of Advanced Research in Chemical Science (IJARCS), 2, 80-84. Retrieved from http:www.arcjournals.org.

3. Desai, A., Shah, S., Goyal, S., \& Prasad, A. (2018). Simulation and Energy Optimization of Ammonia Synthesis Loop. (5).2394-5370. India. Retrieved from http://www.internationaljournalssrg.org

4. Bland, M.J. (2015). Optimization of an Ammonia Synthesis Loop. Investigation of a Novel Approach for Optimization of Integrated Plants. NTNU. Toondheim Norwegian University of Science and Technology. Retrieved from http://folk.ntnu.no

5. Bicer, Y. (2017). Investigation of Novel Ammonia Production Options Using Photoelectrochemical Hydrogen. Canada, Retrieved from https://ir.library.dc.uoit.ca.

6. Benion, E. \& Ruder, J. (2013). Growing demand for fertilizer keeps prices high; Beyond the Numbers: Global Economy, (2)2. U.S. Bureau of Labor Statistics. Retrieved from http:// www.bls.gov/opub/btn/volume-2/pdf/growingdemand-for -fertilizer-keep-prices-high.pdf

7. Jaja, Z., Akpa, J.G., \& Dagde, K.K. (2020).Optimization of Crude Distillation Unit Case Study of the Port Harcourt Refining Company. Advances in Chemical Engineering and Science, 10, 123-134.

8. Akpa, J.G., \& Raphael, N.R. (2014b). Optimization of Ammonia Synthesis Converter. World Journal of Engineering \& Technology WJET. (2), 305-313. Retrieved from http://dx.doi.org/10.4236/wjet.2014.24032

9. Lundgren, M.K., \& Hillestad, M. (2016). Incorporating Ammonia Synthesis for an Offshore Gas-To-Liquid Process. Norway. Retrieval from https://brage.bibsys.no/ 